\title{
Combination of laser microdissection, 2D-DIGE and MALDI-TOF MS to identify protein biomarkers to predict colorectal cancer spread
}

\author{
Chandra Kirana ${ }^{1,2^{*}} \mathbb{0}$, Lifeng Peng ${ }^{3}$, Rose Miller ${ }^{4}$, John P. Keating ${ }^{5}$, Corinne Glenn ${ }^{5}$, Hongjun Shi², \\ T. William Jordan ${ }^{3}$, Guy J. Maddern' and Richard S. Stubbs ${ }^{2}$
}

\begin{abstract}
Biomarkers are urgently required to support current histological staging to provide additional accuracy in stratifying colorectal cancer (CRC) patients according to risk of spread to properly assign adjuvant chemotherapy after surgery. Chemotherapy is given to patients with stage III to reduce the risk of recurrence but is controversial in stage II patients. Up to $25 \%$ of stage II patients will relapse within 5 years after tumor removal and when this occurs cure is seldom possible. The aim of this study was to identify protein biomarkers to stratify risk of spread of CRC patients. Laser micro-dissection was used to isolate cancer cells from primary colorectal tumors of stage II patients which did or did not metastasize within 5 years after surgical resection. Protein expression differences between two groups of tumors were profiled by 2D-DIGE with saturation CyDye labeling and identified using MALDI-TOF mass spectrometry. Evaluation of protein candidates was conducted using tissue micro array (TMA) immunohistochemistry on 125 colorectal tumor tissue samples of different stages. A total of 55 differentially expressed proteins were identified. Ten protein biomarkers were chosen based on $p$ value and ratio between non metastasized and metastazised groups and evaluated on 125 tissues using TMA immunohistochemistry. Expression of HLAB, protein 14-3-3 $\beta$, LTBP3, ADAMTS2, JAG2 and NME2 on tumour cells was significantly associated with clinical parameters related to tumour progression, invasion and metastasis. Kaplan-Meier survival curve showed strong expression of six proteins was associated with good CRC specific survival. Expression of HLAB, ADAMTS2, LTBP3, JAG2 and NME2 on tumour cells, was associated with tumour progression and invasion, metastasis and CRC specific survival may serve as potential biomarkers to stratify CRC patients into low and high risk of tumour metastasis. Combined methods of laser microdissection, 2D DIGE with saturation labelling and MALDI-TOF MS proved to be resourceful techniques capable of identifying protein biomarkers to predict risk of spread of CRC to liver.
\end{abstract}

Keywords: Colorectal cancer, Prognosis, Biomarkers, Proteomics, Liver metastasis

\section{Introduction}

Colorectal cancer (CRC) remains the leading cause of cancer deaths in the Western countries. The incidence and mortality of CRC are also rising in all developing countries [1,2]. Metastatic dissemination from primary tumor accounts for over $90 \%$ of all colorectal cancer death

\footnotetext{
*Correspondence: chandra.kirana@adelaide.edu.au

${ }^{1}$ Discipline of Surgery, The Queen Elizabeth Hospital, Basil Hetzel Research Institute, University of Adelaide, 37a Woodville Road, Woodville, SA 5011, Australia

Full list of author information is available at the end of the article
}

[3]. Adjuvant chemotherapy has been shown to provide a significant improvement in patient survival, however this advantage is not available for all patients who could benefit from it due to inability of current standard method to accurately predict prognosis. Adjuvant chemotherapy for stage II CRC patients is still regarded as controversial [4-6]. About $25 \%$ of stage II CRC patients will develop metastasis after surgical removal of their primary tumor mainly to liver and $50-60 \%$ of stage III CRC patients will develop metastasis [7]. The overall survival rate for stage II CRC patients 5 years after surgery is approximately $70-80 \%$ and that for stage III patients is $30-60 \%$ [8].

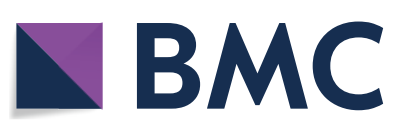

(c) The Author(s) 2019. This article is distributed under the terms of the Creative Commons Attribution 4.0 International License (http://creativecommons.org/licenses/by/4.0/), which permits unrestricted use, distribution, and reproduction in any medium, provided you give appropriate credit to the original author(s) and the source, provide a link to the Creative Commons license, and indicate if changes were made. The Creative Commons Public Domain Dedication waiver (http://creativecommons.org/ publicdomain/zero/1.0/) applies to the data made available in this article, unless otherwise stated. 
Classic disease staging, which is currently the key prognostic indicator for CRC, involves examination of margin, depth of penetration of tumor through bowel wall and degree of lymph node involvement. Patient survival is strongly influenced by lymph node involvement. Recently histopathological features which include depth of tumor invasion in the wall of the colon, lymphovascular invasion (LVI), perineural invasion (PNI), poorly differentiated tumors, $\geq 13$ lymph nodes sampled, bowel obstruction and localized perforation have been added to further define stage II CRC patients as high risk group [9].

Recovery and evaluation of lymph nodes in the resection specimen are, however, influenced by the method and quality of surgical resection, quality of pathologic evaluation, tumor related factors and patient factors [10, 11]. Variation in the assessment of lymph node status could lead to under-staging and as a result a falsely nodenegative patient may not receive the potential benefit of adjuvant therapy. It is well recognized that staging by light microscopy alone is not sufficiently accurate to predict spread as significant variation with respect to clinical outcome exists within currently used stages.

Questions remaining to be answered include which patients will benefit from adjuvant chemotherapy and what chemotherapy to use to give most benefit for the patients. There is therefore urgent need for histological staging to be supported by molecular profiling of tumors to provide additional accuracy in stratifying patients for better disease management and ultimately improved survival.

Molecular profiling has been applied to explore prognostic signatures between patients [12, 13]. While results of some studies have been advanced to clinical use, others have failed to identify specific signatures, and have resulted in loss of confidence in the overall approach. In particular, tissue heterogeneity between patients contributes significantly to the "noise" and variability of samples. Non-cancerous cells within tumors such as fibroblasts, immune cells and blood cells have their own unique expression profile and differences in the proportions of these cells between tumor samples can strongly influence the overall molecular profile of the tumor, effectively masking any cancer cell-specific profile. Laser microdissection (LMD) allows populations of cells to be analyzed separately, minimizing contamination by other cell types, thereby reducing variation and allowing much more relevant and consistent comparison to be undertaken [14]. Two-dimensional differential gel electrophoresis (2D-DIGE) has been one of the approaches used in proteomic analysis [15-17]. The major advantages of DIGE are high sensitivity and linearity of the dyes utilized leading to significant reduction of inter-gel variability. The combined used of LMD and 2D-DIGE increases the potential for unambiguous identification of differentially expressed proteins while reducing biological variability and bias from inter gel variation and also minimizing contamination from non-tumor tissue. In addition, the use of a pooled internal standard increases quantification accuracy and statistical confidence $[15,16]$. Saturation CyDye labeling of cysteine residues has been developed to improve the detection limits for proteins which are only approximately $5 \%$ of proteins present for the minimal labeling method. Saturation labeling has been shown to be at least 10 times more sensitive than minimal labeling, and in theory, should increase the potential for detecting low abundance proteins [17].

The aim of this study was to identify proteins differentially expressed between tumors from stage II CRC patients that tumor had metastasized or not metastasized within 5 years after removal of primary tumors. Selected candidates were then evaluated by TMA immunohistochemistry on tumor sections from patients with known clinical pathological parameters including survival times.

\section{Methods \\ Surgical specimen tissue samples used for protein biomarker discovery}

Primary colorectal tumors were collected from 11 sporadic stage II CRC patients whose tumors had not metastasized in 5 years after surgery (NM) and eight patients whose tumors had metastasized within 5 years postsurgery (M). All patients used in this study underwent surgical resection of their tumors at Wakefield Hospital, Wellington, New Zealand in 1998 to 2008. Tumor specimens were collected directly from theatre and immediately snap-frozen in liquid nitrogen and stored at $-80^{\circ} \mathrm{C}$ until used. Tissue collection and study was approved by the Central Regional Ethics Committee, Wellington in New Zealand, in accordance with the Helsinki Declaration of 1975.

Clinical samples and data sets used on this current study are not publicly available due to patient consent and Ethics but are available from the corresponding author on reasonable request.

\section{Data availability statement}

Clinical samples and data sets used on this current study are not publicly available due to patient consent and Ethics but are available from the corresponding author on reasonable request.

\section{Laser microdissection}

Tumour cells were isolated using LMD (Leica LMD6000, Leica Microsystem). Briefly, frozen tumour tissue was embedded in optimal cutting temperature (OCT) 
compound (Leica Microsystems, Wetzlar, Germany), cut into $20 \mu \mathrm{m}$ thick sections using Leica CM1850 UV Cryostat (Leica Microsystems) at $-20{ }^{\circ} \mathrm{C}$ and mounted onto PET-membrane steel frame slides (Leica Microsystems). The sectioned tissues were fixed with $70 \%$ ethanol for $30 \mathrm{~s}$, and stained in Harris' haematoxylin (VWR, England) for $30 \mathrm{~s}$ then rinsed in water and air dried. All staining procedures were carried out on ice with all solutions supplemented with fresh $1 \mathrm{mM}$ phenylmethanesulfonyl fluoride (Sigma, St Louis, MO, USA). The estimated total protein yield from one thousand cells was approximately one $\mu \mathrm{g}$ protein.

\section{Protein extraction and CyDye Fluor saturation dye labelling}

Microdissected specimens were lysed in $100 \mu \mathrm{L}$ lysis buffer (7 M urea, $2 \mathrm{M}$ thiourea, 4\% (w/v) [(3-cholamidopropyl) dimethylammonio]-1-propanesulfonate (CHAPS), $30 \mathrm{mM}$ Tris (pH 8.5)). The lysates were centrifuged at 13,000 rpm for $10 \mathrm{~min}$ and the supernatants were collected. The proteins were purified using 2D-Cleanup kit (GE Healthcare, Uppsala, Sweden), and re-dissolved in $10 \mu \mathrm{L}$ of the above lysis buffer for 2D-DIGE analysis. Protein concentrations were determined using Bradford microplate assay (Bio-Rad, Hercules, CA, USA).

Originally there were $11 \mathrm{NM}$ and eight $\mathrm{M}$ tissue samples. Three of the 11 NM samples were too low in protein yield, and thus their resulting protein samples were pooled into one sample for 2D-DIGE analysis. Ultimately, nine protein samples from the NM patient group which consisted of eight individual samples and one pooled sample from three patients of low protein yield were used for 2D-DIGE analysis. Similarly four protein samples were obtained from the $\mathrm{M}$ patient group which consisted of three individual samples and one pooled sample from four patients for 2D-DIGE. One sample from the metastasized patient group was discarded because the protein concentration was too low.

CyDye DIGE Fluor saturation dye (GE Healthcare, Uppsala, Sweden) was used to label the proteins according to the manufacturer's instructions. Briefly $5 \mu \mathrm{g}$ protein extract was reduced with $2 \mathrm{nmol}$ tris(2-carboxyethyl) phosphine for one $h$ and then incubated with $4 \mathrm{nmol}$ of CyDye for $30 \mathrm{~min}$. The individual protein samples from microdissected tumour tissues ( $9 \mathrm{NM}$ and $4 \mathrm{M}$ ) were labelled with Cy5. The internal standard, a pool composed of equal amount of proteins from all the samples $(9$ $\mathrm{NM}$ and $4 \mathrm{M}$ ), was labelled with Cy3 dye. All the labeling experiments were carried out in the dark at $37^{\circ} \mathrm{C}$.

\section{Two-dimensional differential gel electrophoresis}

Five microgram of the internal standard labeled with $\mathrm{Cy} 3$ was added to $5 \mu \mathrm{g}$ of each of the individual Cy5-labeled protein samples. This protein sample was then diluted with the rehydration buffer [7 $\mathrm{M}$ urea, $2 \mathrm{M}$ thiourea, $4 \%$ w $/ \mathrm{v}$ CHAPS, $1 \%$ (v/v) pharmalyte $\mathrm{pH} 3-11,0.2 \%$ $(\mathrm{w} / \mathrm{v})$ dithiothreitol (DTT)] to a final volume of $200 \mu \mathrm{L}$. Eleven $\mathrm{cm}$ pH 3-11 non-linear Immobiline ${ }^{\mathrm{TM}}$ Drystrips (GE Healthcare) were placed in contact with the protein sample in the rehydration buffer overnight at room temperature in the dark. Isoelectric focusing (IEF, the first dimension of electrophoresis) was carried out using an Ettan IPGphor (GE Healthcare) as instructed by the manufacturer. Following IEF, the strips were equilibrated in equilibrium buffer (100 mM Tris $\mathrm{pH}$ 8.0, $6 \mathrm{M}$ urea, $2 \%$ SDS, 30\% glycerol) containing $0.5 \%$ DTT, and subsequently $4.5 \%$ iodoacetamide, for $10 \mathrm{~min}$ each. The equilibrated strips were electrophoresed on standard continuous SDS-PAGE gels (Criterion ${ }^{\mathrm{TM}} \mathrm{XT} 4-12 \%$ Bis Tris precast gel, Bio Rad) at $200 \mathrm{~V}$ for $50 \mathrm{~min}$. The SDS PAGE gels were scanned using a fluorescent Fujifilm FLA-5100 scanner (Fujifilm, Tokyo, Japan) with $50 \mu$ and 12 bit resolution. A $532 \mathrm{~nm}$ laser and a PBG/570DF20 emission filter were used to scan the Cy3 images and a 635 laser and a DBR1/R665 emission filter were used to scan the Cy5 images.

Delta 2D software (version 3.6, DECODON GmbH, Greifswald, Germany) was used to analyze the 2D-DIGE images. Gel images were warped using the In-Gel Standard Warping Strategy with all Cy3 internal standard gel images warped to the master gel image using the EXACT mode. Gel images were fused and spot detection was carried out on the fused gel image to produce a consensus spot pattern. All spot quantities were normalized to the internal standard resulting in quantities described by the formula \%V (Spot X of sample A) = rel V (Spot X of sample A)/rel V (Spot X of internal standard), where rel V is the absolute volume of the spot divided by the cumulative absolute volume of all spots on the same image. Differentially expressed proteins were determined by Student's $t$ test based on $\log 2$ transformed protein spot quantities with $p$ value $\leq 0.05$ and the ratio of the protein spots' quantities of a matched protein in NM over M fold change $\geq 1.5$ or $\leq 0.67$.

\section{Protein identification}

Briefly, $400 \mu \mathrm{g}$ of the pooled proteins from all samples were separated on a $2 \mathrm{D}$ gel as above but stained with Coomassie brilliant blue solution $(0.05 \%$ colloidal CBB G-250, 17\% ammonium sulfate, $2 \%$ orthophosphoric acid, 34\% methanol) overnight and scanned using a Molecular Dynamics Scanner, Personal Densitometer SI (Sunnyvale, CA, USA) with $50 \mu$ and 12 bit resolution. Proteins spots of interest were excised using a $1.5 \mathrm{~mm}$ diameter One Touch Plus Spot Picker (The Gel Company, San Francisco, CA, USA). In-gel digestion of protein 
spots was performed as described previously [18]. Briefly, the gel spots were placed in a 96-well plate and detained in $0.1 \mathrm{~mL}$ of destaining solution (50 $\mathrm{nM}$ ammonium bicarbonate, $50 \%$ methanol) overnight. Gel plugs were washed three times in the destaining solution for $20 \mathrm{~min}$ each and finally washed with acetonitrile. Spots were air dried in a SpeedVac (for $60 \mathrm{~min}$ and then digested in $5 \mu \mathrm{L}$ $20 \mathrm{mM}$ ammonium bicarbonate with $0.1 \mu \mathrm{g}$ sequencing grade bovine trypsin (Roche Diagnostic, Manneheim, Germany) for five h at RT. Protein digests were extracted with $20 \mu \mathrm{L}$ of $0.1 \%$ trifluoroacetic acid in $50 \%$ acetonitrile twice and subsequently with $100 \%$ acetonitrile for $20 \mathrm{~min}$ each. The combined $60 \mu \mathrm{L}$ extracts were transferred to a new 96-well plate and air dried for at least $14 \mathrm{~h}$. Dried peptides were reconstituted in $1 \mu \mathrm{L}$ of saturated $\alpha$-cyano4-hydroxycinnamic acid (Sigma-Aldrich) solution containing $0.1 \%$ trifluoroacetic acid, $50 \%$ acetonitrile and $0.05 \%$ Calibration mixture 2 (Sequazyme $^{\mathrm{TM}}$ Peptide Mass Standard Kit, Applied Biosystems, CA, USA) and deposited on the surface of a matrix-assisted laser desorption ionization time of flight mass spectrometry (MALDITOF MS) plate (Applied Biosystems). MALDI-TOF MS was performed using a Voyager-DE PRO Biospectometry $^{\mathrm{TM}}$ Workstation (Applied Biosystems) as described previously [19]. Spectra were acquired using positive reflector mode with the following voltage setting: accelerating 20,000 V; grid, 75\%; guide wire, 0.005; delay time, 180 ns. Each spectrum consisted of 110 laser shots and mass range from 800 to $3500 \mathrm{Da}$. Spectra were processed using Data Explorer ${ }^{\mathrm{TM}}$ (Applied Biosystems). Three peaks from Calibration Mixture 2 of Sequazyme ${ }^{\mathrm{TM}}$ Peptide Mass Standards (1296.6853, 2093.0867 and 2465.1989) were used for internal calibration. Following peak deisotoping, a peak list of monoisotopic peptide masses was generated using a peak detection threshold ranging from two to $10 \%$ of maximum peak area. The resulting monoisotopic peptide masses were searched against the UniProtKB human protein database as of 1 November 2009 using Aldente (http://kr.ezpasy.org/tools/alden te/) with the following searching parameters: maximum missed tryptic cleavage 1 , static carboxymidomethylation modification of cysteine $(+57.02 \mathrm{Da})$ and dynamic oxidation of methionine $(+15.99 \mathrm{Da})$, peptide mass tolerance $0.2 \mathrm{Da}$.

\section{Tissue microarray and immunohistochemical stain}

Initially, five tissue microarray (TMA) blocks containing a total of $126 \mathrm{CRC}$ cases were constructed. Each TMA consisted of up to 26 tissue cores with a single tissue core per patient tumour. Before constructing TMA, a four $\mu \mathrm{m}$ thick section was obtained from each tumour block, stained with haematoxylin and eosin and examined by a pathologist (Rose Miller). Areas of sampling
(AOS) were defined and marked on the microscope slide by the pathologist and used to guide the location of tissue of interest for core punching. TMA was constructed using the Beecher Automated Tissue Arrayer (ATA-27, Beecher Instruments, USA). A tissue core with a diameter of one $\mathrm{mm}$ was punched from the donor tissue block under guidance of the reference slides and transferred to a recipient paraffin block (array margin of $10 \times 20 \mathrm{~mm}$ ).

Four $\mu \mathrm{m}$ thick tissue sections were cut from each TMA block. Tissue sections were serially rehydrated. Antigen retrieval was performed by submerging the slides in sodium citrate buffer (10 $\mathrm{mM}$ sodium citrate, $0.05 \%$ Tween 20, $\mathrm{pH} 6.8$ ) in a pressure cooker for $10 \mathrm{~min}$ at boiling point. After cooling to room temperature, tissue sections were incubated in $3 \% \mathrm{H}_{2} \mathrm{O}_{2}$ in Phosphate Buffer Saline-Tween-20 (PBS-T) for $10 \mathrm{~min}$ to block endogenous peroxidase. Staining was performed using R.T.U Vectastain ${ }^{\circledR}$ Universal Quick kit (Vector Laboratories, Inc, Burlingame, CA) as follows. Briefly sections were sequentially blocked in $2.5 \%$ normal horse serum for $10 \mathrm{~min}$, incubated in primary antibody diluted in Phosphate Buffer Saline (PBS) for $1 \mathrm{~h}$, washed in PBS-T for five min, biotinylated in pan-specific universal secondary antibody for $10 \mathrm{~min}$, washed in PBS, incubated in streptavidin/peroxidase complex for $5 \mathrm{~min}$, washed in PBS and incubated in the DAB substrate kit. Primary antibodies for candidate proteins (Table 2) were purchased from Santa Cruz 14-3-3 $(\mathrm{A}-6)$ (sc-25276) at 1:40; nm23-H2 (L-14) (sc-14789) 1:150; MRCL3/MRCL2 (A-20) (sc9449) at 1:50; SRPX (N-18) (sc-10700) at 1:100; Wnt-5a (C-16) (sc-23698) at 1:50; Jagged2 (H-143) (sc-5604) at 1:100; ADAMTS-2 (18Q) (sc-100479) at 1:200; MHC class I (F-3) (sc-55582) at 1:600; LTBP-3 (H-21) (sc98276) at 1:250 and RECK (28) (sc-136270) at 1:30. Slides were counterstained by dipping in hematoxylin three times, rinsed with water, dehydrated in xylene and finally mounted with DPX- mounting media (IHC World, LCC).

\section{Image analysis and scoring}

Expression of 10 proteins (Table 1) in this study was graded and scored blind by two pathologists (Rose Miller and Corinne Glenn). The intensity of proteins was scored from 1 to 3 with one for weak or none, two for moderate and three for strong and correlated with clinical parameters [20].

\section{Statistical analysis}

Student's $t$ test was used to assess differential expressions of proteins in tumor cells between non-metastasized and metastasized groups. Statistical analyses on the expressions of proteins in tumor tissues were performed using SPSS (version 17). The association between protein immunoreactivities and patient clinicopathological 
Table 1 Differentially expressed proteins of interest detected by 2D-DIGE that were chosen for evaluation by immunohistochemistry

\begin{tabular}{|c|c|c|c|c|c|c|c|}
\hline No. & Gene name & $\begin{array}{l}\text { Uniprot } \\
\text { accession } \\
\text { number }\end{array}$ & Protein name & $\begin{array}{l}\text { Fold } \\
\text { change } \\
\text { (NM/M)* }\end{array}$ & $p$ value (NM/M) & $\begin{array}{l}\text { Peptides } \\
\text { matched }\end{array}$ & $\begin{array}{l}\text { Protein } \\
\text { sequence } \\
\text { coverage (\%) }\end{array}$ \\
\hline 1 & LTBP3 & Q9NS15 & $\begin{array}{l}\text { Latent-transforming growth factor beta binding } \\
\text { protein } 3\end{array}$ & 1.7 & 0.05 & 19 & 16 \\
\hline 2 & $H L A B$ & P30475 & $\begin{array}{l}\text { HLA class } 1 \text { histocompatibility antigen, B39 alpha } \\
\text { chain }\end{array}$ & 2.5 & 0.03 & 8 & 21 \\
\hline 3 & ADAMTS2 & 095450 & $\begin{array}{l}\text { A disintegrin and metalloproteinase with thrombos- } \\
\text { podin motifs } 2\end{array}$ & 1.5 & 0.01 & 14 & 22 \\
\hline 4 & RECK & 095980 & Reversion-inducing cysteine-rich protein & 1.8 & 0.03 & 15 & 19 \\
\hline 5 & WNT5A & P41221 & Wnt-5a protein & 0.56 & 0.06 & 9 & 22 \\
\hline 6 & $14-3-3-\beta$ & P31946 & 14-3-3 protein beta/alpha & 0.67 & 0.05 & 9 & 37 \\
\hline 7 & SRPX & P78539 & Sushi repeat-containing protein SRPX & 1.5 & 0.02 & 14 & 26 \\
\hline 8 & NME2 & P22392 & Nucleoside diphosphate kinase $\mathrm{B}(\mathrm{nm} 23 \mathrm{H} 2)$ & 1.6 & 0.005 & 8 & 38 \\
\hline 9 & MRLC 3 & P19105 & Myosin regulatory light chain MRLC3 & 0.67 & 0.025 & 7 & 46 \\
\hline 10 & JAG2 & Q9Y219 & Protein Jagged-2 & 1.7 & 0.05 & 23 & 20 \\
\hline
\end{tabular}

Note: Student's $t$ test based on log2 transformed spot volumes between non-metastasized (NM) and metastasized (M) tumors

parameters were assessed by $x^{2}$ test. The impact of individual protein on patient survival was examined by Kaplan-Meier curve analysis and the statistical significances were determined using log-rank test. A $p$ value $\leq 0.05$ was considered significant.

\section{Results}

\section{Identification of differentially expressed proteins} by 2D-DIGE

A total of 1123 protein spots were detected and matched on the analytical gels between the two groups by 2D-DIGE. Out of 1123 protein spots, 55 showed significantly different volume changes between the non-metastasized and metastasized groups $[p \leq 0.05$, fold change $(\mathrm{NM} / \mathrm{M}) \geq 1.5$ or $\leq-1.5]$. Figure 1 shows the unsupervised hierarchical clustering analysis of the two groups based on the volumes of differentially abundant protein spots. The protein expression profiles in the metastasized group showed some consistent changes among individuals. The protein expression profiles in the non-metastasized group and metastasized group showed to be heterogeneous among its individual. Protein expression patterns between two groups of sample were distinct.

\section{Evaluation of differentially expressed proteins} by immunohistochemistry

Ten differentially expressed proteins of interest detected by 2 D-DIGE were chosen based on low $p$ value $(p \leq 0.05)$ and high fold change between the non-metastasized (NM) and metastasized (M) patient groups of colorectal cancer within 5 years after the primary tumors were removed and also their known roles in cancer progression and metastasis and further evaluated using TMA immunohistochemistry of 125 colorectal tumor tissue samples. A summary of these proteins is presented in Table 1.

The expression (weak, moderate and strong) of two representative proteins, HLAB and LTBP3 on CRC tissue using immunohistochemistry is illustrated in Fig. 2.

The association between clinical pathological parameters with the expression levels of ten proteins in tumor tissues of 125 TMA immunohistochemistry is shown in Table 2. Expression of six proteins, HLAB, 14-3-3 3 , ADAMTS2, LTBP3, NME2 and JAG2 on colorectal tumour cells significantly correlated with some clinical pathologic factors, whileWNT5A, MRLC3, RECK and SRPX showed no association.

HLAB was significantly associated with histological grade $(p=0.020)$; PNI $(p=0.017)$ and cause of CRC death $(p=0.025)$. Expression of $14-3-3 \beta$ protein significantly correlated with mucinous $(p=0.001)$, histological grade $(p=0.031)$ and depth of tumour penetration $(p=0.041)$. LTBP3 expression on tumour cells was significantly associated with distant metastasis and CRC cause of death $(p=0.003$ and $\mathrm{p}=0.005$ respectively). ADAMTS2 was significantly correlated with distant metastasis $(p=0.013), 5$ year disease recurrence $(p=0.041)$ and at border line for CRC specific cause of death $(p=0.055)$. JAG2 expression on tumour cells was significantly associated with mucinous $(p=0.044)$ and LVI $(p=0.038)$ and NME2 were significantly correlated with histological grade and LVI at $p=0.032$ and $p=0.048$ respectively.

The association of protein expression with cancer specific survival was assessed by univariate analysis using Kaplan-Meier curve and log-rank test. Kaplan 


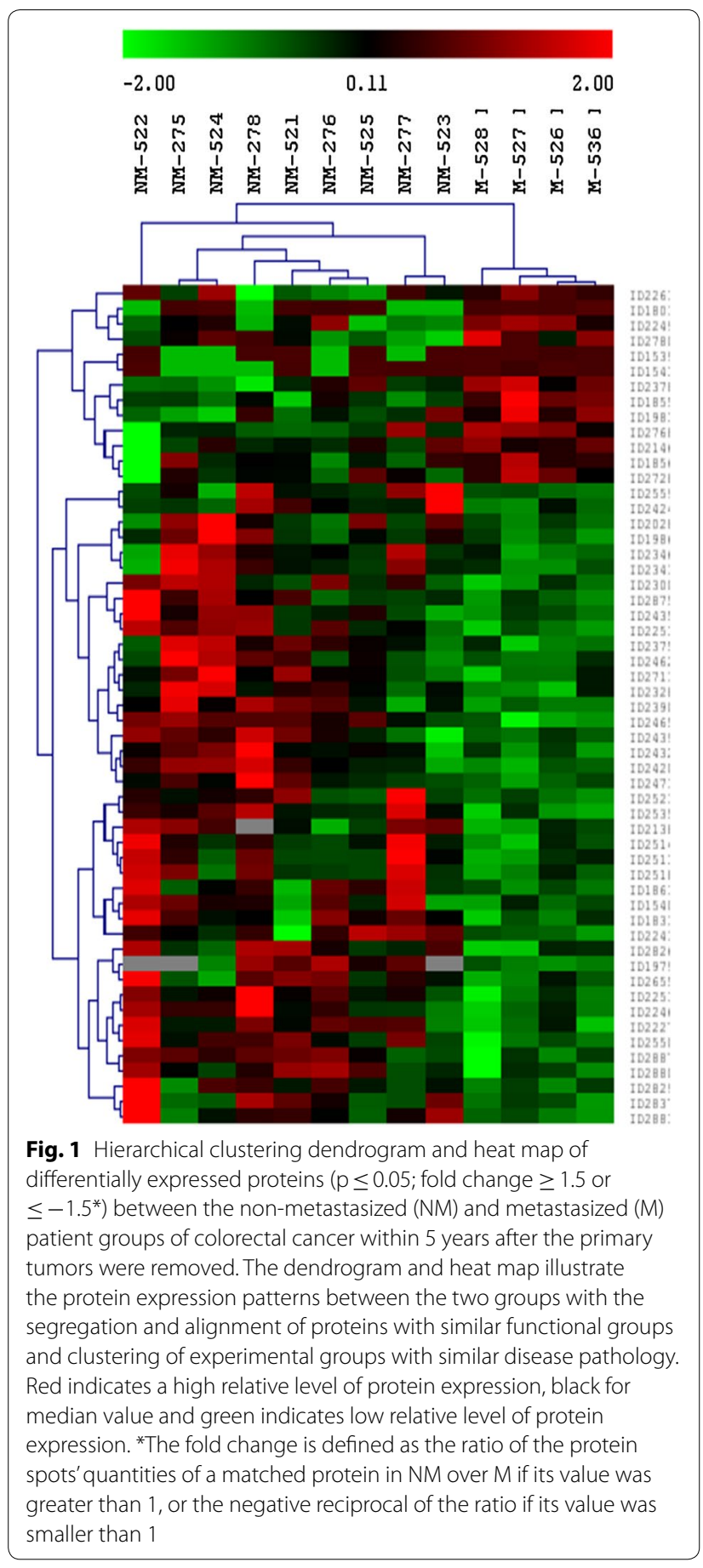

Meier survival curve showed the expression of HLAB, 14-3-3 $\beta$, ADAMTS2, LTBP3, NME2 and JAG2 on colorectal tumour cells associated with CRC specific survival. Strong expression of the proteins was associated with good CRC specific survival. The association between expression of the proteins and CRC specific survival also shown on CRC patients with the stage 2 and 3 (Figs. 3 and 4).

\section{Discussion}

CRC remains a major public health burden worldwide. Australia and New Zealand have the highest incidence rate of CRC, which account the third most common diagnosed cancer and the second cause of cancer death [21]. The incidence of CRC is also rising in the developing countries $[1,2]$. About $15-30 \%$ of patients with stage II and $50-60 \%$ of patients with stage III will eventually develop distant metastases after their primary tumor is removed which then results in poor outcomes and subsequent death [22]. Adjuvant chemotherapy, however, is only common practice for stage III patients and still debated for stage II patients [4-6]. Classical histological staging remains the gold standard practice to measure CRC prognosis. The American Society of Clinical Oncology [7] has added histopathological features including depth of tumor infiltration, < 13 lymph nodes sampled, perineural invasion, lymphovascular involvement and poorly differentiated histology tumor to further subgroup stage II patients into low and high risk category and therefore adjuvant chemotherapy administration is considered. However, the benefit of adjuvant chemotherapy for stage II patients in improving 5 year survival was only about 5\%. Additional molecular markers are urgently required to further identify high risk patients so that adjuvant chemotherapy will have benefit to the patients.

In this study we have combined LMD and 2D-DIGE application to profile proteins from tumor cells of stage II CRC patients whose tumors did or did not metastasize within 5 years of first surgical intervention. Tissue heterogeneity between patients and presence of non-cancerous cells within tumors contributes significantly to the "noise" and variability of samples thereby strongly affect molecular profile of tumour cells. Laser microdissection allows populations of cells to be analyzed separately to minimize contamination from other cell types, thereby reducing variation and allowing more relevant and consistent comparison [14].

The 2D-DIGE approach is used to minimize variations between gels and improve reproducibility which can be problematic in traditional 2-DE. Increased confidence in detection of proteins was facilitated by running an internal standard in every gel. The strategy of saturation dye labeling is superior to minimal label dye approach where limited quantities of protein sample are available [17]. Due to limited protein yield available from LMD samples we used saturation dye labeling and 2D-DIGE for this program. Saturation labeling has been shown to be more sensitive than minimal labeling in protein detection, which in theory should increase the potential for detecting low abundance protein [23]. Protein profiles from metastasized samples were more homogenous than those of non-metastasized samples. Proteins 


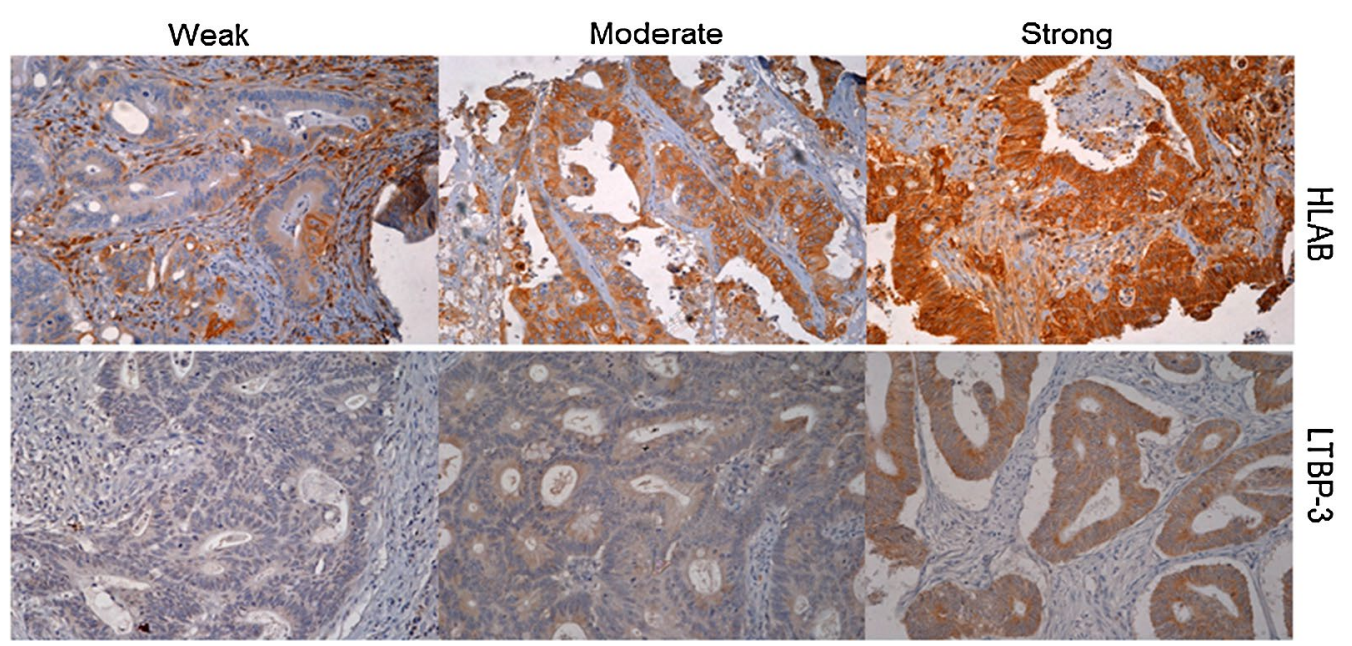

Fig. 2 Representative CRC tissues showing low, moderate and strong staining pattern of HLAB (top) and LTBP3 (bottom) proteins on tumour cells by immunohistochemistry (DAB substrate brown) ( $\times 20$ objective). Sections were counterstained with hematoxylin (blue)

with differential expression patterns between metastasized and non-metastasized tumor were markedly observed. Six of the $10(60 \%)$ proteins examined using TMA immunohistochemistry, HLAB, protein 14-3-3 $\beta$, LTBP3, ADAMTS2, JAG2 and NME2, were significantly associated with clinical parameters which have shown to relate with tumor progression, invasion and metastasis. Four proteins, WNT5A, MRLC3, RECK and SRPX did not have association with clinical parameters used in this study. Using combination of LMD and saturation dye labeling and 2D-DIGE, we identified proteins which have been reported to associate with cancer using more advanced as well as 2-DE proteomic techniques. Protein 14-3-3 $\beta$ was found by Zang et al. [24] using more advanced proteomic techniques while NME2 was identified differentially expressed in lung adenocarcinoma and bone metastasis lung cancer using 2-DE and MALDITOF-MS [25]. In addition, we also identified ADAMTS2 and LTBP3. These proteins have been reported to associate with cancer progression, however, the expression has not been previously reported in clinical samples.

HLAB belongs to major histocompatibility complex proteins (MHC) class I. MHCs are cell surface glycoproteins that play a fundamental role in the regulation of immune responses. It has been widely known that the availability of MHC class I on tumor cell membrane is important for enabling CD8+ cytotoxic T-lymphocytes recognition and binding to tumor antigen peptides [26, 27]. The loss of MHC class I results in escape from recognition and destruction by CTLs. CD8+ cells play crucial roles in anti-tumor responses. Down-regulation of HLA class I in cancers has been reported to associate with poor prognosis for example in rectal cancer [28] and ovarian cancer [29]. Our study showed that colorectal tumor which did not metastasize had stronger expression of HLAB than tumor which metastasis. Loss or low expression of HLAB in CRC tissue was significantly associated with distant metastasis, disease recurrence and CRC specific survival. In addition, Kaplan Meier survival analysis showed that no expression of HLAB on tumour cells showed worst prognosis.

ADAMTS (A disintegrin and metalloproteinase with thrombospondin motifs) enzymes are secreted multidomain matrix-associated zinc metalloendopeptidases. There are 19 ADAMTs. ADAMTS2, 3 and 14 are procollagen $\mathrm{N}$-endopeptidase enzymes. They play crucial roles in collagen type I and III fibrils maturation and formation [30]. We found that the expression of ADAMTS2 was down-regulated in the tumour cells of patients that metastasized compared to those that did not metastasize. Expression of ADAMTS2 was significantly associated with distant metastasis and at borderline value with cause of colorectal cancer specific death. Using Kaplan-Meier survival curve and logrank analysis showed that patients whose tumor loss of ADAMTS2 showed significantly shorter cancer survival than those whose tumors expressed ADAMTS2. ADAMTS2 was reported to have anti proliferation and anti angiogenic activity and induced apoptosis independent of its catalytic activity [31]. In addition, ADAMTS1 was described as having tumor-protective effects and angiogenesis inhibitory enzyme due to its capacity to restrain endothelial cell proliferation [32]. We reported for the first time that the expression of ADAMTS2 in clinical samples, CRC tissue and blood, significantly associated with liver metastasis and good 
Table 2 Correlations of protein expression levels with clinicopathological features

\begin{tabular}{|c|c|c|c|c|c|c|c|c|c|c|c|}
\hline Clinico-path parameters & No of cases (\%) & HLAB & $14-3-3 \beta$ & LTBP-3 & ADAMTS2 & Wnt-5a & MRLC $2 / 3$ & Jagged-2 & $\mathrm{nm} 23 \mathrm{H} 2$ & SRPX & RECK \\
\hline Age & & 0.923 & 0.273 & 0.132 & 0.246 & 0.437 & 0.173 & 0.644 & 0.745 & 0.145 & 0.559 \\
\hline$<65$ & $35(29)$ & & & & & & & & & & \\
\hline$\geq 65$ & $84(71)$ & & & & & & & & & & \\
\hline Gender & & 0.556 & 0.363 & 0.178 & 0.938 & 0.562 & 0.709 & 0.515 & 0.866 & 0.681 & 0.215 \\
\hline $\mathrm{F}$ & $59(50)$ & & & & & & & & & & \\
\hline M & $60(50)$ & & & & & & & & & & \\
\hline Tumor location & & 0.230 & 0.318 & 0.231 & 0.444 & 0.317 & 0.078 & 0.589 & 0.736 & 0.534 & 0.036 \\
\hline Colon & $82(69)$ & & & & & & & & & & \\
\hline Rectum & $37(31)$ & & & & & & & & & & \\
\hline Histological type & & 0.106 & $0.001^{*}$ & 0.952 & 0.621 & 0.192 & 0.792 & $0.044^{*}$ & 0.158 & 0.526 & 0.659 \\
\hline Non mucinous & $102(86)$ & & & & & & & & & & \\
\hline Mucinuo & $16(14)$ & & & & & & & & & & \\
\hline Histological grade & & $0.020^{*}$ & $0.031^{*}$ & 0.743 & 0.326 & 0.266 & 0.402 & 0.646 & $0.032^{*}$ & 0.149 & 0.327 \\
\hline High grade & $95(81)$ & & & & & & & & & & \\
\hline Low grade & $23(191)$ & & & & & & & & & & \\
\hline Vascular invasion & & 0.556 & 0.200 & 0.500 & 0.730 & 0.279 & 0.584 & $0.038^{*}$ & $0.048^{*}$ & 0.401 & 0.166 \\
\hline Negative & $90(76)$ & & & & & & & & & & \\
\hline Positive & $29(24)$ & & & & & & & & & & \\
\hline Perineural invasion & & $0.017^{*}$ & 0.466 & 0.194 & 0.457 & 0.300 & 0.598 & 0.664 & 0.080 & 0.925 & 0.747 \\
\hline Negative & $109(92)$ & & & & & & & & & & \\
\hline Positive & $9(8)$ & & & & & & & & & & \\
\hline TNM stages & & 0.394 & 0.226 & 0.647 & 0.664 & 0.508 & 0.403 & 0.374 & 0.147 & 0.184 & 0.257 \\
\hline I & $20(17)$ & & & & & & & & & & \\
\hline$\|$ & $42(36)$ & & & & & & & & & & \\
\hline III & $34(29)$ & & & & & & & & & & \\
\hline IV & $21(18)$ & & & & & & & & & & \\
\hline Distant metastasis & & 0.307 & 0.850 & $0.003^{*}$ & $0.013^{*}$ & 0.503 & 0.833 & 0.808 & 0.418 & 0.681 & 0.210 \\
\hline No & $89(75)$ & & & & & & & & & & \\
\hline Yes & $29(25)$ & & & & & & & & & & \\
\hline Nodal status & & 0.227 & 0.417 & 0.403 & 0.336 & 0.894 & 0.101 & 0.283 & 0.413 & 0.463 & 0.194 \\
\hline Negative & $66(58)$ & & & & & & & & & & \\
\hline Positive & $47(42)$ & & & & & & & & & & \\
\hline Depth of invasion & & 0.426 & $0.041^{*}$ & 0.497 & 0.855 & 0.095 & 0.152 & 0.054 & 0.092 & 0.110 & 0.245 \\
\hline $\mathrm{T} 1 / \mathrm{T} 2$ & $23(20)$ & & & & & & & & & & \\
\hline $\mathrm{T} 3 / \mathrm{T} 4$ & $93(80)$ & & & & & & & & & & \\
\hline 5-year recurrence ${ }^{\#}$ & & 0.104 & 0.120 & 0.075 & $0.041^{*}$ & 0.671 & 0.781 & 0.763 & 0.761 & 0.673 & 0.654 \\
\hline Recurrence free & $58(79)$ & & & & & & & & & & \\
\hline Recurrence & $15(21)$ & & & & & & & & & & \\
\hline Cause of death & & $0.025^{*}$ & 0.139 & $0.005^{*}$ & 0.055 & 0.380 & 0.650 & 0.488 & 0.144 & 0.390 & 0.265 \\
\hline CRC & $37(30)$ & & & & & & & & & & \\
\hline Other cause & $87(70)$ & & & & & & & & & & \\
\hline
\end{tabular}

${ }^{*} p<0.05$ is considered significant

\# Presence of absence of local or distant metachronous recurrence within 5 year follow-up

(See figure on next page.)

Fig. 3 The expression of HLAB (A1) 14-3-3 protein beta (B1) and LTBP3 (C1) of the tumour cells of stage 1, 2, 3 CRC patients in a cohort of 125 tumor tissues is associated with CRC specific survival. Strong expression of HLAB, 14-3-3 protein beta and LTBP3 on cancer cells of stage 2 CRC patients showed better CRC specific survival than moderate and or weak expression of the proteins respectively (A2, B2, C2) 

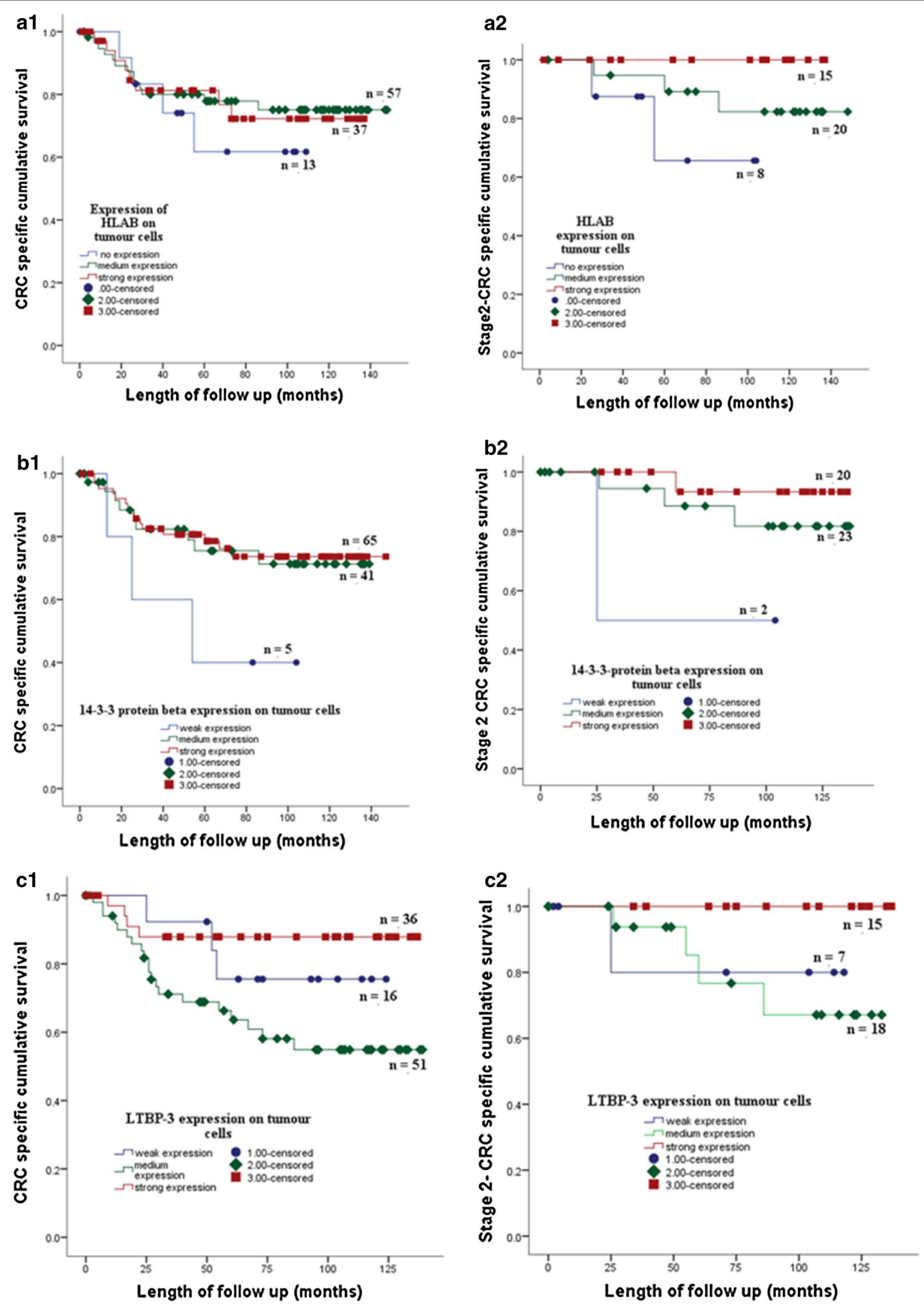


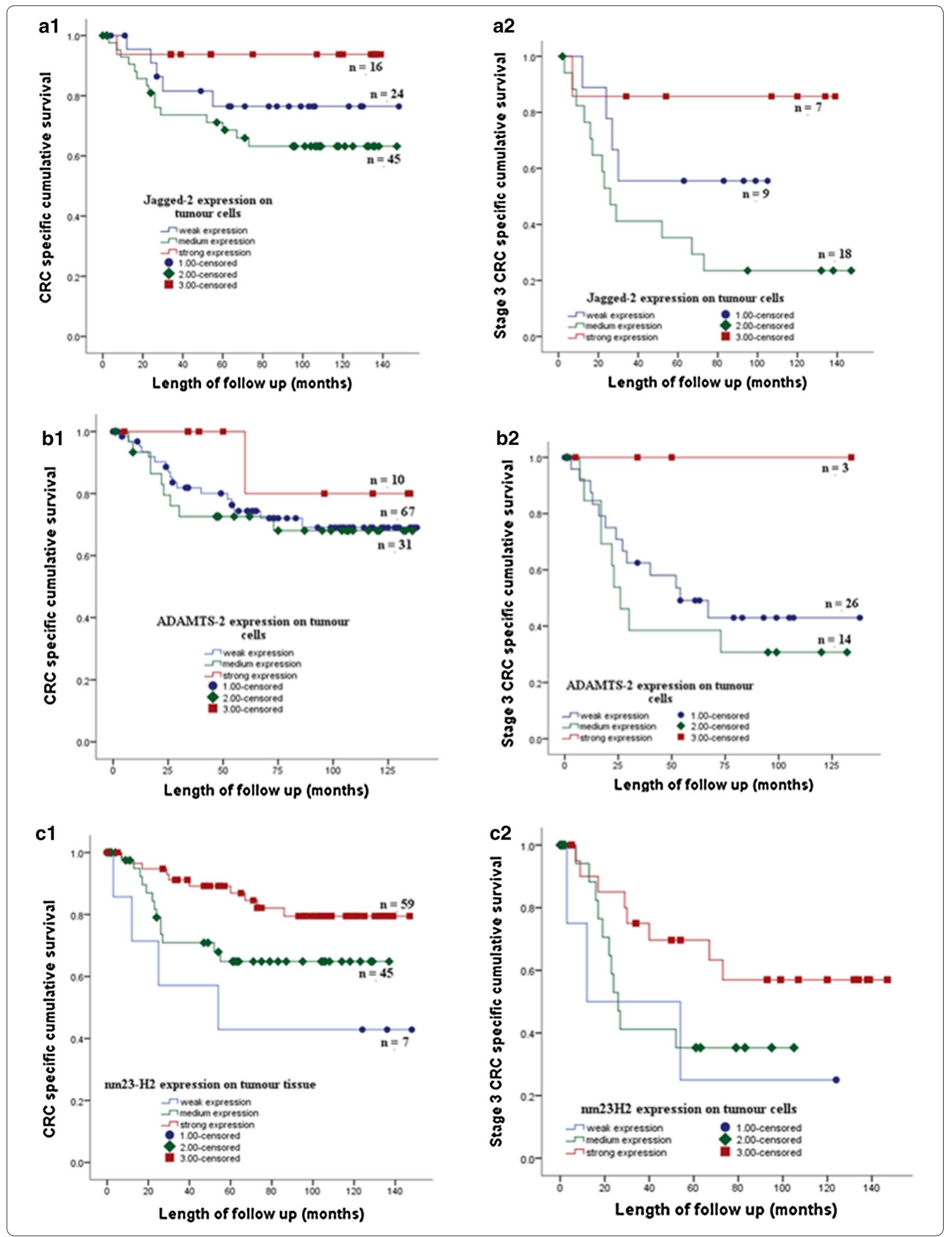


(See figure on previous page.)

Fig. 4 The expression of JAG2 (A1) ADAMTS2 (B1) and NME2 (C1) of the tumour cells of stage 1, 2, 3 CRC patients in a cohort of 125 tumor tissues is associated with CRC specific survival. Strong expression of JAG2, ADAMTS2 and NME2 on cancer cells of stage 3 CRC patients showed better CRC specific survival than moderate and weak expression of the proteins respectively $(\mathbf{A 2}, \mathbf{B 2}, \mathbf{C 2})$

prognosis. Using both cell culture and a mouse model of vascularization of tumours, Dubail et al. [31] showed that ADAMTS2 inhibited proliferation and angiogenesis of endothelial cells and that the growth of tumor with ADAMTS2 treatment had less vascularization compared to control animals.

Ligand-induced Notch signaling has been implicated in cancer biology. JAG2 is one of the ligands in Notch signaling. In mammalian cells, Notch signaling consists of four receptors (Notch1-Notch4), three delta like ligands (DLL1, DLL3 and DLL4) and two serrate-like ligands (JAG1 and JAG2) [33].

Although it has been reported that up regulation of JAG2 expression was associated with the progression of tumour including in pancreatic [34], lung [35] and bladder cancer [36], the role of JAG2 in cancer remains unclear [33, 36]. In contrast, our findings showed that expression of JAG2 on tumour cells significantly associated with histological type of tumour, and vascular invasion. Strong expression of JAG2 in tumour cells correlated with good CRC specific survival.

14-3-3 proteins are highly conserved protein family. There are seven family members of the proteins in mammals, $-\beta,-\gamma,-\varepsilon,-\sigma,-\zeta,-\tau$ and $-\eta$. 14-3-3 proteins bind a variety of functionally diverse signaling proteins including phosphatases, trans-membrane receptors and kinases which contribute to survival and apoptotic signaling, cell growth, tumour suppression and cancer development [37]. Loss of 14-3-3 $\sigma$ has been reported to have tumoursuppressing activities in breast cancer [38]. In contrast $14-3-3-\zeta$ has been suggested to contribute to tumour invasion and migration [37]. Our study found that the expression 14-3-3- $\beta$ protein on tumour cells significantly associated with histological type and grade of CRC tumour and depth of invasion of tumour cells. Stronger expression of 14-3-3- $\beta$ protein associated with better CRC specific survival.

NM23 family proteins are highly conserved proteins. There were eight genes in the human genome encoding NM23 family proteins and suggested as suppressor of tumour metastasis [39]. NME2 protein has anti tumorigenic activity thru blocking ERK pathway [40]. Our study showed that the expression of NME2 in tumour cells significantly associated with histological grade of tumour and vascular invasion. Strong expression of NME2 in tumour cells indicated good CRC specific survival.
LTBPs are important component of extracellular matrix (ECM) that interact with fibrillin microfibrils. There are four LTBPs isoform in human (LTBP1, -2, -3 and -4) [41]. Our findings identified LTBP3 in tumour cells. LTBP-3 on tumour cells of stage II patients whose tumour did not metastasize and those whose tumour metastasized to the liver were differentially expressed. The expression of LTBP3 in the tumour cells significantly associated with distant metastasis and CRC cause of death. Strong expression of LTPB3 in tumour cells showed good CRC survival. LTBP3 was reported [41] to promote early metastasis during cancer cell dissemination by inducing intravasation supporting angiogenic vasculature within developing primary tumours. Report on LTBP3 in clinical samples has not been reported elsewhere. The role of LTBP3 in cancer is understudied.

\section{Conclusions}

Combined methods of laser microdissection, 2D DIGE with saturation labelling and MALDI TOF/TOF proved to be resourceful methods capable to show proteins differences of stage II CRC patients whose tumours did not metastasis with those whose tumours metastasized to liver. Proteins, HLAB, ADAMTS2, LTBP3, JAG2 and NME2 were significantly associated with tumor progression, vascular invasion and distant liver metastasis. These proteins are potential biomarkers to current classic pathological staging for separating patients with low and high risk of tumour spread. Individual or combined proteins may potentially serve as additional marker to current classic staging to identify distant liver metastasis and provide be better therapeutic CRC management to reduce cancer spread and decrease mortality of colorectal cancer.

\section{Authors' contributions}

CK designed the study and carried out the LMD, 2D-DIGE, participated in MALDI-TOF/TOF, TMA, IHC and drafted the manuscript. RM examined the histopathology of samples for LMD, JPK compiled the clinical parameter data base of patients used for TMA, CG and RM scored the TMA. RS conceived the study, HS participated in TMA and compiled clinical parameters and statistical analysis, LP participated in MALDI-TOF MS and preparation of manuscript, TWJ participated in the identification of proteins and review manuscript, GM participated in preparation of manuscript. All authors read and approved the final manuscript.

\section{Author details \\ 1 Discipline of Surgery, The Queen Elizabeth Hospital, Basil Hetzel Research Institute, University of Adelaide, 37a Woodville Road, Woodville, SA 5011,} Australia. ${ }^{2}$ Wakefield Biomedical Research Unit, Wakefield Clinic, Wakefield 
Hospital, Wellington, New Zealand. ${ }^{3}$ Centre for Biodiscovery and School of Biological Sciences, Victoria University of Wellington, Wellington, New Zealand. ${ }^{4}$ Department of Pathology and Molecular Medicine, Otago University of Wellington, Wellington, New Zealand. ${ }^{5}$ Coastal and Coast District Health Board, Department of Surgery, Wellington Hospital, Wellington, New Zealand.

\section{Acknowledgements}

The authors would like to thank study participants, Mr. John Groom and nurses at Wakefield Hospital for assisting with sample collections. This study was supported by NZ Cancer Society, Cancer Society Wellington Division, Wellington Medical Research Foundation, Wakefield Gastroenterological Research Trust and Wakefield Clinic. CK would like to thank Associate Professor Diane Kenwright and Professor Brett Delahunt from the Department of Pathology and Molecular Medicine, University of Otago Wellington for giving me office and laboratory accesses while working on this project.

\section{Competing interests}

The authors declare that they have no competing interests.

\section{Ethic approval and consent to participants}

Informed, written consent was obtained from all patients. Approval for the tissue collection and study was given by the Central Regional Ethics Committee, Wellington in New Zealand, in accordance with the Helsinki Declaration of 1975.

\section{Funding}

This study was funded by NZ Lottery Grants, NZ Cancer Society, Cancer Society Wellington Division, Wellington Medical Research Foundation, Wakefield Gastroenterological Research Trust and Wakefield Clinic.

\section{Publisher's Note}

Springer Nature remains neutral with regard to jurisdictional claims in published maps and institutional affiliations.

Received: 13 August 2018 Accepted: 9 January 2019

Published online: 22 January 2019

\section{References}

1. Sung JJ, Lau JY, Goh KL, Leung WK. Asia Pacific Working Group on Colorectal Cancer Increasing incidence of colorectal cancer in Asia: implications for screening. Lancet Oncol. 2005;6(11):871-6.

2. Favoriti P, Carbone G, Greco M, Pirozzi F, Pirozzi EM, Corcione F. Worldwide burden of colorectal cancer: a review. Updates Surg. 2016;68:7-11.

3. Christofori G. New signals from the invasive front. Nature. 2006:441(7092):444-50.

4. Zaniboni AR, Labianca R. Adjuvant therapy for stage II colon cancer: an elephant in the living room? Ann Oncol. 2004;15(9):1310-8.

5. Johnston PG. Stage II colorectal cancer: to treat or not to treat. Oncologist. 2005;10(5):332-4

6. Kannarkatt J, Joseph J, Kurniali PC, Al-Janadi A, Hrinczenko B. Adjuvant chemotheraphy for stage II colon cancer: a clinical dilemma. J Oncol Pract. 2017;13(4):233-42.

7. Benson AB, Schrag D, Somerfield MR, Cohen AM, Figueredo AT, Flynn PJ, et al. American Society of Clinical Oncology recommendations on adjuvant chemotherapy for stage II colon cancer. J Clin Oncol. 2004;22(16):3408-19.

8. Le Voyer TE, Sigurdson ER, Hanlon AL, Mayer RJ, Macdonald JS, Catalano $P J$, et al. Colon cancer survival is associated with increasing number of lymph nodes analyzed: a secondary survey of intergroup trial INT-0089. J Clin Oncol. 2003;21(15):2912-9.

9. Varghese A. Chemotherapy for stage II colon cancer. Clin Colon Rectal Surg. 2015;28(4):256-61.

10. Pusztaszeri M, Matter M, Kuonen A, Bouzourene $H$. Nodal staging in colorectal cancer: should distant lymph nodes be recovered in surgical specimens? Hum Pathol. 2009;40(4):552-7.

11. Choi HK, Law WL, Poon JT. The optimal number of lymph nodes examined in stage II colorectal cancer and its impact of on outcomes. BMC Cancer. 2010;10:267.
12. Coate LE, John T, Tsao MS, Shepherd FA. Molecular predictive and prognostic markers in non-small-cell lung cancer. Lancet Oncol. 2009;10(10):1001-10.

13. Zhu CQ, Pintilie M, Strumpf FA, Der SD, Jurisica I, Tsao MS. Understanding prognostic gene expression signatures in lung cancer. Clin Lung Cancer. 2009;10(5):331-40.

14. Johann DJ, Rodriguez-Canales J, Muukherjee S, Prieto DA, Hanson JC, Emmert-Buk M, et al. Approaching solid tumor heterogeneity on a cellular basis by tissue proteomics using laser capture microdissection and biological mass spectrometry. J Proteome Res. 2009;8(5):2310-8.

15. Kirana C, Ward T, Jordan TW, Rawson P, Royds J, Shi HJ, et al. Compatibility of toluidine blue with laser microdissection and saturation labeling DIGE. Proteomics. 2009;9:485-90.

16. Alban A, David SO, Bjorkesten L, Anderson C, Sioge E, Lewis S, et al. A novel experimental design for comparative two-dimensional gel analysis: two-dimensional difference gel electrophoresis incorporating a pooled internal standard. Proteomics. 2003;3(1):36-44.

17. Shaw J, Rowlinson R, Nickson J, Stone T, Sweet A, Williams K, et al. Evaluation of saturation labelling two-dimensional difference gel electrophoresis fluorescent dyes. Proteomics. 2003;3(7):1181-95.

18. Shi H, Hood KA, Hayes MT, Stubbs RS. Proteomic analysis of advanced colorectal cancer by laser capture microdissection and two-dimensional difference gel electrophoresis. J Proteomics. 2011;75(2):339-51.

19. Shi H, Stubbs RS, Hood KA. Characterization of de novo synthesized proteins released from human colorectal tumour explants. Electrophoresis. 2009;30(14):2442-53.

20. Shi H, Hayes MT, Kirana C, Miller R, Keating J, Macartney-Coxson D, Stubbs R. TUFM is a potential new prognostic indicator for colorectal carcinoma. Pathology. 2012:44(6):506-12.

21. Australian Institute of Wealth. Cancer Compendium: information and trend by cancer type. 2016. www.aihw.gov.au.

22. Ju JH, Chang SC, Wang HS, Yang SH, Jiang JK, Chen WC, et al. Changes in disease pattern and treatment outcome of colorectal cancer: a review of 5474 cases in 20 years. Int J Color Dis. 2007;22(8):855-62.

23. Alfonso P, Canamero M, Fernandez-Carbonie F, Nunez A, Casal Jl. Proteome analysis of membrane fractions in colorectal carcinomas by using 2D-DIGE saturation labeling. J Proteome Res. 2008;7(10):4247-55.

24. Zhang Y, Liu Y, Ye Y, Shen D, Zhang H, Huang H, Li S, Wang S, Ren J. Quantitative proteome analysis of colorectal cancer-related differential proteins. J Cancer Res Clin Oncol. 2017;143(2):233-41.

25. Yang M, Sun Y, Sun J, Wang Z, Shou Y, Yao G, Gu Y, Zhang H, Zhao H. Differentially expressed and survival-related proteins of lung adenocarcinoma with bone metastasis. Cancer Med. 2018;7(4):1081-92.

26. Cruz I, Mejjer CJ, Walboomers JM, Snijders PJ, Van der Waal I. Lack of MHC class I surface expression on neoplastic cells and poor activation of the secretory pathway of cytotoxic cells in oral squamous cell carcinomas. $\mathrm{Br}$ J Cancer. 1999;81(5):881-9.

27. Garcia-Lora A, Martinez M, Algarra I, Faforio JJ, Garrido F. MHC class I-deficient metastatic tumor variants immunoselected by T lymphocytes originate from the coordinated downregulation of APM components. Int J Cancer. 2003;106(4):521-7.

28. Speetjens FM, de Bruin EC, Morreau H, Zeestraten ECM, Putter H, van Krieken $\mathrm{JH}$, et al. Clinical impact of HLA class I expression in rectal cancer. Cancer Immunol Immunother. 2008;57(5):601-9.

29. Rolland P, Deen S, Scott I, Durrant L, Spendiove I. Human leukocyte antigen class I antigen expression is an independent prognostic factor in ovarian cancer. Clin Cancer Res. 2007;13(12):3591-6.

30. Beckhouche M, Colige A. The procollagen N-proteinases ADAMTS2, 3 and 14 in pathophysiology. Matrix Biol. 2015;44-46:46-53.

31. Dubail J, Kesteloot F, Deroanne C, Motte P, Lambert V, Rakic JM, et al. ADAMTS-2 functions as anti-angiogenic and anti-tumoral molecule independently of its catalytic activity. Cell Mol Life Sci. 2010;67(24):4213-32.

32. Kuno K, Bannai K, Hakozaki M, Matsushima K, Hirose K. The carboxylterminal half region of ADAMTS1 suppresses both tumorigenicity and experimental tumor metastatic potential. Biochem Biophys Res Commun. 2004;319:1327-33.

33. D'Souza B, Miyamoto A, Weinmaster $G$. The many facets of Notch ligands. Oncogene. 2008;27:5148-67.

34. Mullendore MF, Koorstra JB, Li YM, Offerhause GJ, Fan Z, Henderson CM, Matsui W, Eberhart CG, Maitra A, Feldmann G. Ligan-dependent Notch 
signalling is involved in tumor initiation and tumor maintenance in pancreatic cancer. Clin Cancer Res. 2009;15:229-2301.

35. Li W, Liu M, Feng Y, Huang YF, Xu YF, Che JP, Wang GC, Zheng JH. High expression of Notch ligand Jagged is associated with the metastasis and recurrence in urothelial carcinoma of bladder. Int J Clin Exp Pathol. 2013;6:2430-40.

36. Yang $Y$, Ahn YH, Gibbons DL, Zang Y, Lin W, Thilagaathan N, Alvarez CA, Moreira DC, Creighton CJ, Gregory PA, Goodall GJ, Kurie JM. The Notch ligand Jagged 2 promotes lung adenocarcinoma metastasis through a miR-200-dependent pathway in mice. J Clin Investig. 2011;121:1373-85.

37. Morrison DK. The 14-3-3 proteins: integratiors of diverse signaling cues that impact cell fate and cancer development. Trends Cell Biol. 2008:19:16-23.
38. Umbricht CB, Evron E, Gabrielson E, Ferguson A, Marks J, Sukumar S. Hypermethylation of 14-3-3 $\sigma$ (stratifin) is an early event in breast cancer. Oncogene. 2001;20:3348-53.

39. Ouatas T, Salerno T, Palmieri D, Steeg PS. Basic and translational advances in cancer metastasis: NM23. J Bioenerg Biomembr. 2003;35:73-9.

40. Lee MY, Jeong WJ, Oh JW, Choi KY. NM23H2 inhibits EGF-and Ras-induced proliferation of NIH3T3 cells by blocking the ERK pathway. Cancer Lett. 2009;275:221-6.

41. Deryugina El, Zajac E, Zilberberg L, Muramatsu T, Joshi G, Dabovic B, Rifkin D, Quigley JP. LTBP3 promotes early metastatic events during cancer cell dissemination. Oncogene. 2018;37:1815-29.
Ready to submit your research? Choose BMC and benefit from:

- fast, convenient online submission

- thorough peer review by experienced researchers in your field

- rapid publication on acceptance

- support for research data, including large and complex data types

- gold Open Access which fosters wider collaboration and increased citations

- maximum visibility for your research: over $100 \mathrm{M}$ website views per year

At BMC, research is always in progress.

Learn more biomedcentral.com/submissions 